\title{
Health Education Needs of First Visit Pregnant Women in Antenatal Clinics in Khayelitsha, South Africa
}

\author{
Thabani M. Noncungu \\ https://orcid.org/0000-0002-3638-7097 \\ University of the Western Cape \\ South Africa \\ tnoncunga@uwc.ac.za
}

\author{
Jennifer Chipps \\ https://orcid.org/0000-0002-7895-4483 \\ University of the Western Cape \\ South Africa \\ jchipps@uwc.ac.za
}

\section{Abstract}

Health education is a key component of first antenatal visits. The aim of this study was to describe the health education needs of pregnant women on their first visit to antenatal clinics in Khayelitsha, South Africa. A quantitative descriptive survey was conducted, to investigate the lifestyle, pregnancyrelated, psycho-social health education needs and predictors of health education needs during pregnant women's first antenatal clinic visit. The research was conducted at two purposively selected antenatal clinics in Khayelitsha, a low-income suburb in Cape Town, South Africa. The respondents were considered eligible for the study if they were Xhosa speaking, pregnant, older than 18 years, making a first visit to antenatal care, and able to complete their consent form or provide consent from parents or relatives. Respondents were eligible for the study regardless of the number of pregnancies they had previously had, their age and previous medical conditions. There were a total of $240(92 \%)$ respondents. Overall pregnancyrelated health education needs were rated the highest $(\mathrm{m}=4.0$, [95\%CI3.954.09]), with information on how the baby grows and develops during pregnancy $(\mathrm{m}=4.6$, [95\% CI4.5-4.7]) the highest. The lowest rated health information needs were testing for HIV and prevention thereof $(\mathrm{m}=3.5$, [95\% CI3.3-3.7]) and how to use seat belts during pregnancy $(\mathrm{m}=3.2$, [95\% CI3.0-3.4]). A lack of awareness of the duration of pregnancy predicted significantly higher overall health education needs and lifestyle education needs. The study recommends that pregnant women should be provided with

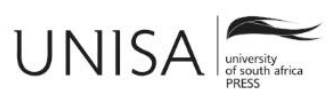


prioritised health information during their first antenatal visit, especially given the high risk of late bookings for first antenatal visits.

Keywords: antenatal education; antenatal visit; health education needs; pregnancyrelated issues; pregnant women

\section{Introduction}

Ensuring adequate maternal and child health care is a global challenge, especially in resource scarce countries (Chib 2010). In South Africa, both the public and private health sectors offer antenatal care service to pregnant women as a routine preventative health care service (Hofmeyr and Mentrop 2015; Song et al. 2013). The public health sector antenatal services have been available, free of charge, to all pregnant women since the 1994 post-apartheid era (Naledi, Schneider, and Barron 2011).

Pregnancy is a period of high risk for women and can be associated with ill-health and death (Gudayu, Woldeyohannes, and Abdo 2014). Antenatal care services are important to ensure good health of pregnant women (Bjelke et al. 2016). The visit should allow health risks to be identified, health education in the form of information, advice and encouragement to be provided, and to timeously treat minor problems during pregnancy (Al-Ateeq and Al-Rusaiess 2015).

Health education during antenatal visits is an important element of antenatal care (AlAteeq and Al-Rusaiess 2015). It provides an opportunity for health information exchange between health care professionals and pregnant women to identify protective and risk factors and to provide pregnancy-related health information needs (Brixval et al. 2014). Health education should also prepare women for safe delivery and emergencies during pregnancy (Al-Ateeq and Al-Rusaiess 2015). Health education is especially important during the first visit to an antenatal care clinic, as it is a valuable opportunity to influence the health and well-being of the mother and child during pregnancy, birth and beyond (Maher, Spurling, and Askew 2014).

There is often a gap between delivered health education and the health information needs of pregnant women (Anya, Hydara, and Jaiteh 2008; Hildingsson et al. 2013; Vonderheid, Norr, and Handler, 2007). There is a shortage of published evidence on the specific health education needs of pregnant women, with limited studies on health education in southern Africa (Amenu et al. 2016). International studies have reported that many women either lack knowledge or show a lack of concern for certain health risks in pregnancy (Pérez-Lu, Bayer, and Iguiñiz-Romero 2018), and they often do not 
benefit from health education during antenatal care (Amenu et al. 2016). In South Africa, it has been reported that pregnant women have little knowledge about danger signs and other related health topics (Amenu et al. 2016). One of the reasons for this has been identified as health care professionals spending too much time discussing generic topics such as substance abuse, and not enough on topics related to the needs of the individual pregnant women (Vonderheid et al. 2007). Evidence also suggests that the health education information offered can be unrealistic and conflicting in nature, which may be compounded by how the information is presented (Hardie, Horsburgh, and Key 2014).

A further concern is that existing studies often focus on knowledge, understanding and content of health information provided, but little is known about the health education needs of women attending antenatal care for the first time, especially in resource scarce countries such as South Africa. To address this gap and to develop a profile of the health education needs of pregnant women, a study was conducted to investigate the health education needs of pregnant women during their first visit to antenatal clinics in Khayelitsha in the Western Cape, South Africa.

\section{Statement of the Research Problem}

When pregnant women receive adequate and appropriate health education, there is a resultant increase in antenatal care visits and a reduction of preventable complications (Dako-Gyeke et al. 2013). However, there is concern about the lack of appropriate health education and the provision of information on undesired health topics by health professionals (Dako-Gyeke et al. 2013). There is at times a mismatch between the offered health education, socio-demographic characteristics and desired health information by pregnant women (Hildingsson et al. 2013). This is compounded where work force problems may lead to health care professionals packing too much health education into short appointments, leaving too little time for discussion or fostering trusting relationships (Royal College of Midwives 2013). If this results in not addressing the health information needs of pregnant women, it may lead to frustration, a loss of interest in antenatal visits and possibly seeking other less reliable sources (Ohlendorf, Weiss, and Ryan 2012). This is especially relevant during the first antenatal visit and highlights the need to identify the health education information needs of pregnant women, to ensure that the health education serves its intended goal. 


\section{Objectives of the Study}

The objectives of the study were to describe the lifestyle, pregnancy-related and psycho-social health education needs of pregnant women during their first antenatal visit to primary health care facilities in Khayelitsha.

\section{Research Methodology}

\section{Study Design}

A quantitative descriptive design survey was used to describe the health education needs of pregnant women. The use of a quantitative, descriptive research approach is influenced by the study's objective to describe, explain and predict the education needs of pregnant women during their first antenatal visit.

\section{Research Setting}

The study was conducted in two out of nine purposively selected primary care clinics in Khayelitsha. The two clinics provide 24-hour midwifery services, which include antenatal care, first bookings for pregnant women, and referrals to secondary, district and tertiary hospitals. The clinics are public sector clinics owned by the Western Cape Government and operated by midwives and nurses.

\section{Study Population}

The study population was isiXhosa pregnant women who had their first antenatal visit in the two purposively selected primary health care facilities. The average number of first antenatal women was 36\% (638-650 first attendees).

\section{Sample and Sampling Techniques}

A systematic random sampling procedure was chosen to select pregnant women on their first visit at two antenatal clinics. To ensure the accuracy of the systematic sampling technique, every fourth pregnant woman was given a written number so that the researcher and assistant could easily identify who to approach for participation. The selection of the sample size in the study was based on the inclusion criteria. A total of 271 pregnant women were invited to participate.

\section{Ethical Consideration}

Ethics approval was obtained from the Ethics Committees of the University of the Western Cape and permission to conduct the study was received from the Western 
Cape Department of Health and managers of the specific primary health care facilities. Voluntary informed consent, privacy, confidentiality, respect and justice were ensured throughout the study.

\section{Research Instrument}

A researcher-administered questionnaire, originally developed by Shieh, McDonald and $\mathrm{Ke}$ (2009), was used, with permission, in the study. The researcher-administered questionnaire included patient demographics, obstetric characteristics, and a standard scale determining health information needs, namely the Pregnancy Health Information Needs Scale (PHINS). The PHINS consists of 20 Likert scale items on health education needs in the areas of lifestyle, medication, psycho-social and pregnancyrelated health education. The respondents were asked to rate their level of agreement on the need for health education in these domains, using the five categories scored from 1-5 (disagree very much (1), disagree (2), no opinion (3), agree (4) or agree very much (5)). The scale was scored and completed as per instructions from Shieh et al. (2009) with a higher mean score indicating a higher need for the item. The questionnaire was translated from English into isiXhosa and back, to ensure the translation was meaningful and correct. Content validity was established in the instrument obtained from Shieh et al. (2009). In this study the PHINS scale had an adequate reliability in the South African setting (Cronbach $\alpha=.79$ ).

\section{Data Collection}

The data for the study were collected at the two primary health care antenatal clinics for a period of 11 weeks from May to July 2016. Two isiXhosa research assistants were trained to recruit potential respondents, to provide information about the study and to collect the informed consent to participate in the study. The isiXhosa version of the questionnaire was administered by the main researcher in a quiet room in the antenatal clinics. No incentives were provided. The questionnaire took 40 to 60 minutes per respondent to complete.

\section{Data Analyses}

The study data were entered and analysed using the Statistical Packaging for Social Science for Windows, version 21.0. Descriptive and inferential statistics such as Mann-Whitney, Hierarchical multiple regression tests and preliminary analysis were employed in analysing the significance level of $\mathrm{P}<0.05$. Total mean scores on PHINS items were calculated with $95 \%$ confidence intervals and ranked from highest to lowest. However, incomplete PHINS scales were discarded. 


\section{Results}

\section{Demographics}

A total of 261 women agreed to participate in the study, resulting in a response rate of $92 \%$. Nearly two thirds of the respondents $(52,63.3 \%)$ were 35 years and younger with an average age of 27 years $( \pm 6.0)$. Nearly three quarters $(168,70 \%)$ of the respondents were single, though half reported that they lived with the baby's father $(120,50 \%)$. Three quarters $(182,75.8 \%)$ of the respondents had completed grade eight out of 12 levels of secondary school, and nearly half $(104,43 \%)$ of the respondents were unemployed (Table 1). There were significant differences in demographics by first pregnancy with multigravida women being older, more reported to be married or live with a companion and more were employed (Table 1).

\section{Obstetric Characteristics}

At their first antenatal visit to the clinics, over half $(146,61 \%)$ of the respondents were multigravida, with $156(65 \%)$ being in their first trimester. The gestation age of the pregnancy at first visit was $17.2( \pm 6.3)$ weeks, and most of the respondents $(215,90 \%)$ reported having no medical conditions. Twenty-five of the respondents $(10.4 \%)$ reported having medical conditions (Table 1), these included asthma $(n=14)$, diabetes $(n=9)$ and high blood pressure $(n=2)$. 
Table 1: Demographic characteristics of respondents

\begin{tabular}{|c|c|c|c|c|c|}
\hline Demographics & Primigravida & Multigravida & Total & Test & p-value \\
\hline & $\mathrm{n}=94$ & $\mathrm{n}=146$ & $\mathrm{n}=240$ & & \\
\hline \multicolumn{6}{|l|}{ Maternal age } \\
\hline$<35$ & $69(45 \%)$ & $83(55 \%)$ & $152(63 \%)$ & $U=3.25$ & $\mathrm{p}=.001 *$ \\
\hline$>35$ & $10(11 \%)$ & $78(89 \%)$ & $88(37 \%)$ & & \\
\hline \multicolumn{6}{|l|}{ Maternal status } \\
\hline Single & $77(45 \%)$ & $95(55 \%)$ & $172(72 \%)$ & $U=5.59$ & $\mathrm{p}=.002 *$ \\
\hline Married & $16(23 \%)$ & $52(77 \%)$ & $68(28 \%)$ & & \\
\hline \multicolumn{6}{|l|}{ Educational } \\
\hline Secondary school & $77(37 \%)$ & $130(63 \%)$ & $207(86 \%)$ & $U=7.22$ & $\mathrm{p}=.217$ \\
\hline University/college & $16(49 \%)$ & $17(51 \%)$ & $33(14 \%)$ & & \\
\hline \multicolumn{6}{|l|}{ Occupational status } \\
\hline Unemployed & $65(45 \%)$ & $79(54 \%)$ & $144(60 \%)$ & $U=5.73$ & $\mathrm{p}=.013 *$ \\
\hline Employed & $28(29 \%)$ & $68(71 \%)$ & $96(40 \%)$ & & \\
\hline \multicolumn{6}{|l|}{ Living arrangements } \\
\hline Live alone & $2(17 \%)$ & $10(83 \%)$ & $12(5 \%)$ & $U=7.15$ & $\mathrm{p}=.108$ \\
\hline Companion & $91(40 \%)$ & $137(60 \%)$ & $228(95 \%)$ & & \\
\hline Obstetrics & Primigravida & Multigravida & Total & Test & p-value \\
\hline Number of pregnancies & $94(39 \%)$ & $146(61 \%)$ & $240(100 \%)$ & $U=4.17$ & $\mathrm{p}=.001 *$ \\
\hline \multicolumn{6}{|l|}{ Gestation age on 1 st visit } \\
\hline 1st trimester & $57(36 \%)$ & $99(64 \%)$ & $156(65 \%)$ & $U=7.25$ & $\mathrm{p}=.339$ \\
\hline$>2$ nd trimester & $36(43 \%)$ & $48(57 \%)$ & $84(35 \%)$ & & \\
\hline $\begin{array}{l}\text { Reported medical } \\
\text { conditions at } 1 \text { st visit }\end{array}$ & $9(36 \%)$ & $16(64 \%)$ & $25(10 \%)$ & $U=6.75$ & $\mathrm{p}=.766$ \\
\hline
\end{tabular}

$U=$ Mann-Whitney test, $\mathrm{p}$-value significant at $\mathrm{p}=.05^{*}$

\section{Overall Health Education Needs}

Overall, the respondents reported high levels of agreement on the need for health education (80.5, range: $77.6-83.2)$ on their first visit to the antenatal clinics $(m=4.0 / 5$, [95\% CI 3.95-4.09]). The pregnancy-related health education needs had significantly 
higher levels of agreement of importance than the psycho-social health education needs and lifestyle health education needs (Figure 1).

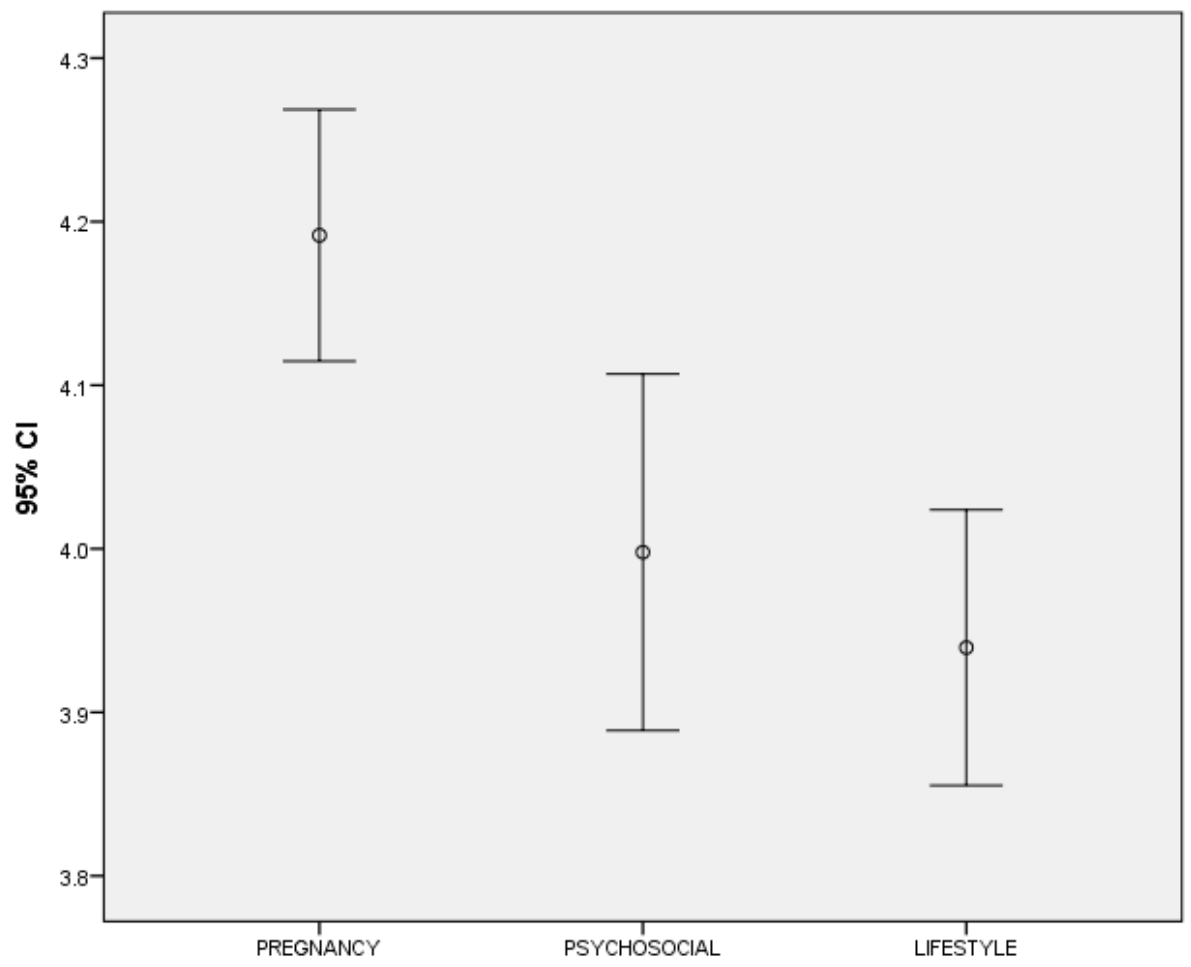

Figure 1: Health education needs by category

Among all the health education needs, how the baby grows and develops during pregnancy and what are the danger signs during pregnancy had significantly higher ratings than all other health education needs ( $\mathrm{p}<.05)$ (Table 2). HIV testing and prevention; how much weight should I gain during pregnancy; and how to use seat belts during pregnancy had the lowest level of agreement and were rated significantly lower than all other items $(\mathrm{p}<.05)$. 
Table 2: Health education information needs

\begin{tabular}{|l|l|r|r|}
\hline Rank & Health education need & Mean(sd) & \multicolumn{1}{|c|}{. CI } \\
\hline & Pregnancy-related health education needs & $\mathbf{4 . 1 9}(\mathbf{0 . 6})$ & {$[\mathbf{4 . 1 1 - 4 . 2 3}]$} \\
\hline 1 & How the baby grows and develops during pregnancy & $4.6(0.8)$ & {$[4.5-4.7]^{*}$} \\
\hline 2 & What are the danger signs during pregnancy & $4.5(0.7)$ & {$[4.5-4.6]^{*}$} \\
\hline 10 & $\begin{array}{l}\text { How to practise safe sex that won't affect baby and } \\
\text { pregnancy }\end{array}$ & $4.1(1.2)$ & {$[4.0-4.3]$} \\
\hline 13 & How to prepare for breast feeding & $4.0(1.4)$ & {$[3.8-4.1]$} \\
\hline 16 & Kinds of safe and unsafe medications & $4.0(1.2)$ & {$[3.8-4.1]$} \\
\hline 17 & What to do if my labour starts early & $3.9(1.4)$ & {$[3.8-4.1]$} \\
\hline & Lifestyle health education needs & $\mathbf{3 . 9 3}(\mathbf{0 . 7})$ & {$[\mathbf{3 . 8 5}-\mathbf{4 . 0 2}]$} \\
\hline 3 & $\begin{array}{l}\text { Information about prenatal vitamins and how much of } \\
\text { them are needed }\end{array}$ & $4.2(1.0)$ & {$[4.1-4.3]$} \\
\hline 4 & How using illegal drugs affects baby and pregnancy & $4.2(1.1)$ & {$[4.1-4.3]$} \\
\hline 5 & What I should or should not eat & $4.2(1.1)$ & {$[4.0-4.3]$} \\
\hline 8 & How to balance rest and activity & $4.1(1.0)$ & {$[4.0-4.2]$} \\
\hline 11 & What birth control methods to use after my pregnancy & $4.1(1.3)$ & {$[3.9-4.2]$} \\
\hline 12 & What are safe exercises for me & $4.0(1.1)$ & {$[3.9-4.2]^{*}$} \\
\hline 14 & How smoking affects the baby and pregnancy & $4.0(1.2)$ & {$[3.8-4.1]$} \\
\hline 15 & How drinking alcohol affects the baby and pregnancy & $4.0(1.3)$ & {$[3.8-4.1]$} \\
\hline 19 & How much (weight) should I gain during pregnancy & $3.4(1.4)$ & {$[3.3-3.6]^{*}$} \\
\hline 20 & How to use seat belts properly during pregnancy & $3.2(1.5)$ & {$[3.0-3.4]^{*}$} \\
\hline & Psycho-social health education needs & $\mathbf{3 . 9 9}(\mathbf{0 . 9})$ & {$[\mathbf{3 . 8 8}-\mathbf{4 . 1 0}]$} \\
\hline 6 & How to deal with stress during pregnancy & $4.2(1.2)$ & {$[4.0-4.3]$} \\
\hline 7 & Physical abuse by their husbands or partners & $4.1(1.1)$ & {$[4.0-4.3]$} \\
\hline 9 & Emotional changes during pregnancy & $4.1(1.2)$ & {$[4.0-4.3]$} \\
\hline 18 & Health education about HIV blood test and prevention & $3.5(1.6)$ & {$[3.3-3.7]^{*}$} \\
\hline & Total scale average score & $\mathbf{4 . 0 2}(\mathbf{0 . 5})$ & {$[\mathbf{3 . 9 5}-\mathbf{4 . 0 9}]$} \\
\hline
\end{tabular}

*Significant at $95 \%$ CI 


\section{Pregnancy-related Health Education Needs}

Pregnancy-related health education needs were measured using six items on the PHINS scale, including information on baby growth and development, danger signs during pregnancy, practising safe sex during pregnancy, breastfeeding, and medication. Two pregnancy-related health education needs had significantly higher levels of agreement than all the others, namely: how the baby grows and develops during pregnancy; and what are the danger signs during pregnancy (Figure 2), which also had the highest level of agreement of all the health education needs.

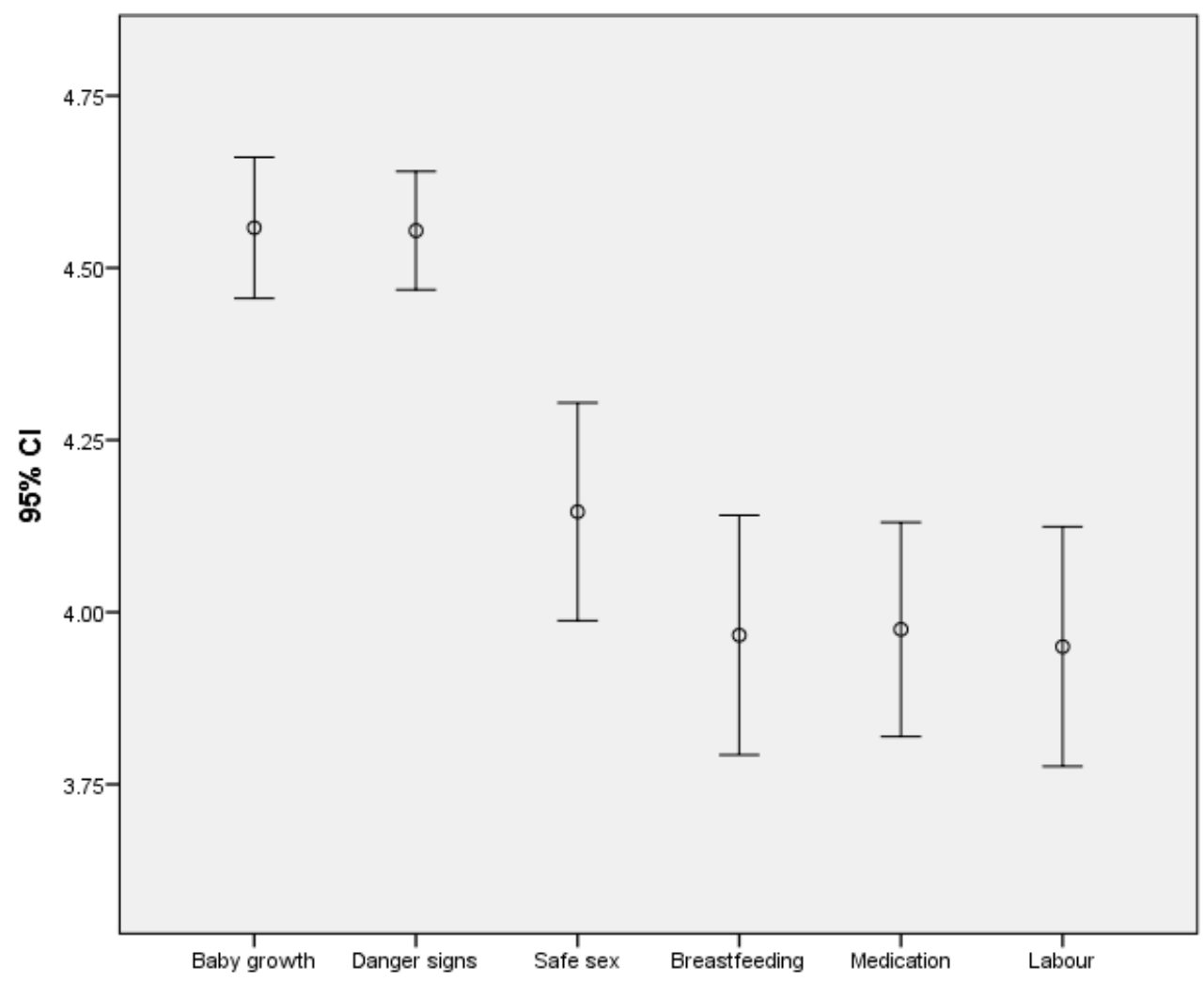

Figure 2: Pregnancy-related health education needs

Although breastfeeding was among the lowest-rated pregnancy-related education needs, there were significant differences between the ratings of health education needs 
for information on breastfeeding in primigravida and multigravida women (4.4(1.0) vs 3.7(1.5), $U=8.5, \mathrm{p}=.001)$. There were also significant differences in primigravida and multigravida women on medication-related health education, with primigravida women rating these higher (4.3(0.9) vs 3.8(1.4), $U=7.8, \mathrm{p}=.049)$. The level of education did impact on pregnancy-related health needs; respondents with only basic education having higher levels of agreement on health education on danger signs (4.6(0.6) vs 4.3(0.8), $U=2.7, \mathrm{p}=.023)$ as a need.

\section{Lifestyle Health Education Needs}

Though respondents had the highest level of agreement on the need for health education about the use of prenatal vitamins during pregnancy in this category, there were no significant differences among the needs for the different lifestyle health education except for knowing how much weight to gain during pregnancy and how to use seat belts safely, which had significantly lower agreement levels. Information on the use of seat belts during pregnancy was the lowest-rated lifestyle health education need. Nonetheless, there were significant differences, with single women having higher levels of agreement on the need for health education on seat belt use in pregnancy than women with partners (3.5(1.5) vs 3.1(1.5), $U=6.8, \mathrm{p}=.041)$. Respondents living on their own also showed higher levels of agreement on health education needs for exercise (4.7(0.5) vs 4.0(1.0), $U=8.6, \mathrm{p}=.019)$. Lastly, significant differences were also noted between respondents with basic and higher education with higher levels of agreement on the need for alcohol health education (4.3(1.3) vs 3.6(1.3), $U=2.5, \mathrm{p}=.008)$.

\section{Psycho-social Education Needs}

The psycho-social education needs were measured using four items on the PHINS scale on dealing with stress, physical abuse, nutrition, emotional changes during pregnancy, and HIV blood tests and prevention. There was no significant difference in agreement on needs for the different areas of psycho-social health education, except the need for HIV testing and prevention health education, which were rated significantly lower.

\section{Predictors of Health Education Needs}

Hierarchical multiple regression was used to assess the ability of characteristics such as first pregnancy and general lack of knowledge regarding pregnancy (measured as unaware of the duration of pregnancy) in predicting the overall health education need and the specific health education need scores (pregnancy, lifestyle, psycho-social 
health education needs) of the respondents (Table 3). Being unaware of the duration of pregnancy significantly predicted higher needs for overall health education and lifestyle health education during pregnancy, and first pregnancy significantly predicted higher needs for pregnancy-related health education (Table 3 ).

Table 3: Predictors of health education needs

\begin{tabular}{|c|c|c|c|c|c|c|c|c|}
\hline \multirow[t]{2}{*}{ Predictor } & \multicolumn{2}{|c|}{\begin{tabular}{|l} 
Overall Health \\
Education Needs
\end{tabular}} & \multicolumn{2}{|c|}{\begin{tabular}{|l} 
Pregnancy Health \\
Education Needs \\
\end{tabular}} & \multicolumn{2}{|c|}{$\begin{array}{l}\text { Lifestyle Health } \\
\text { Education Needs }\end{array}$} & \multicolumn{2}{|c|}{$\begin{array}{l}\text { Psycho-social } \\
\text { Health Education } \\
\text { Needs }\end{array}$} \\
\hline & $\begin{array}{l}\text { Mean } \\
\text { rating }\end{array}$ & $\begin{array}{l}\text { Beta } \\
\text { (p-value) }\end{array}$ & $\begin{array}{l}\text { Mean } \\
\text { rating }\end{array}$ & $\begin{array}{l}\text { Beta } \\
(\mathrm{p} \text {-value })\end{array}$ & $\begin{array}{l}\text { Mean } \\
\text { rating }\end{array}$ & $\begin{array}{l}\text { Beta } \\
\text { (p-value) }\end{array}$ & $\begin{array}{l}\text { Mean } \\
\text { rating }\end{array}$ & $\begin{array}{l}\text { Beta } \\
\text { (p-value) }\end{array}$ \\
\hline \begin{tabular}{|l} 
First \\
pregnancy
\end{tabular} & $\begin{array}{l}4.07 \mathrm{vs} \\
3.99 \\
\end{array}$ & $.066(.306)$ & $\begin{array}{l}4.36 \mathrm{vs} \\
4.08 \\
\end{array}$ & $.222(.001)^{*}$ & \begin{tabular}{|l|}
$3.93 \mathrm{vs}$ \\
3.94 \\
\end{tabular} & $-.013(.841)$ & $\begin{array}{l}3.99 \mathrm{vs} \\
3.99 \\
\end{array}$ & $-.003(.959)$ \\
\hline $\begin{array}{l}\text { Unaware of } \\
\text { duration of } \\
\text { current } \\
\text { pregnancy }\end{array}$ & $\begin{array}{l}4.11 \mathrm{vs} \\
3.94\end{array}$ & $.162(.012)^{*}$ & $\begin{array}{l}4.26 \mathrm{vs} \\
4.11\end{array}$ & $-.122(.053)$ & $\begin{array}{l}4.02 \mathrm{vs} \\
3.85\end{array}$ & $-.132(.042)^{*}$ & $\begin{array}{l}4.1 \mathrm{vs} \\
3.89\end{array}$ & $-.127(.050)$ \\
\hline
\end{tabular}

\section{Discussion}

To our knowledge, this study is among few studies conducted to investigate the health education needs of pregnant women on their first antenatal visit in low-income communities (Shieh et al. 2009; Song et al. 2013). The current study produced three main findings that are essential in understanding the health educational needs of pregnant women at their first visit to antenatal clinics in a primary health care setting. The first finding was respondents' high levels of health education need on their first visit to the antenatal clinics. The need for health education in this study is higher than the overall health education needs reported in the study by Shieh et al. (2009) (80.5, range: 77.6-83.2 vs 72.66; 39-100 (Shieh et al. 2009)). The high reported need for health education during the first visit of pregnant women might be related to the assumption of pregnant women that they have gaps in their health knowledge and therefore require a variety of health education on their first visit (Baron et al. 2017). Furthermore, pregnant women are more likely to have a high number of questions on their first visit as they mostly reinforce written information (McArdle et al. 2015). This is further supported in our study where the strongest predictor for the high needs score for health education was respondents' lack of knowledge about pregnancy (unaware of duration of pregnancy) (Table 3). 
A second key finding was the high reported needs for health education on pregnancyrelated information, especially on topics such as how the baby grows and develops and knowledge about the danger signs during pregnancy. The high need of pregnant women to hear about what to do when labour starts, knowledge on danger signs of pregnancy, and how the baby grows and develops, was comparable to the study of Shieh et al. (2009). The comparability of pregnancy-related information clearly indicates the great need for pregnancy-related information during pregnancy, especially by primigravida. This may be due to their low levels of education, employment status and number of pregnancies, which might lead to poor access of reproductive health-related information, compared to their counterparts from other socio-economic and cultural backgrounds (Solomon et al. 2015). However, health information on what to do when labour starts early, in the current study, was poorly rated compared to previous studies (Shieh et al. 2009).

The third key finding was the low-rated need for health education on the topics of medication during pregnancy (4.0 (1.2)), seatbelt use during pregnancy (3.2 (1.5)), and prevention of HIV and AIDS (3.5 (1.6)) (Table 2), which may have a direct impact on the outcome of pregnancy. Other studies alluded to pregnant women having fewer information wishes on the prevention of HIV and AIDS, claiming that the information is not helpful in decision making regarding the prevention of HIV and AIDS during pregnancy (Vieira et al. 2017). This is more concerning in low-income communities, where greater improvement on general knowledge about HIV and prevention of mother-to-child transmission (PMCT) is needed to decrease HIV transmission (Rochat et al. 2013).

There was a low-rated need for information on medication, which could be due to the small proportion $(10 \%)$ of pregnant women who reported medical conditions. An earlier study conducted by Pisa et al. (2015) in Italy also reported a low (40\%) use of medication by first-time pregnant women who reported different medical conditions including chronic conditions. The study reported that first-time pregnant women who had poor control of their health conditions - or were above the age of 35 years - were more concerned with pregnancy outcome and could recall the used medication for their medical conditions (Pisa et al. 2015). The low reported need for health education on seat belt use could be influenced by the geographic location of the clinics and women's low education levels. Nevertheless, the current study did not evaluate whether the pregnant women had driving licenses. A similar study conducted in Hong Kong reveals that pregnant women with primary or secondary education had low knowledge about the use of seat belts when compared with women with tertiary 
education, and hence could not identify the information needs regarding their safety when travelling with their cars or public transport (Lam, To, and Ma 2016). The low desire for knowledge on seat belt usage shows the necessity for nurses to educate pregnant women on the importance of wearing seat belts when in motor vehicles.

\section{Conclusion}

It is clear from the current study that pregnant women, at their first antenatal visit in low-income communities, have high health education needs, especially on foetal growth and development and danger signs during pregnancy. However, pregnancyrelated health education needs are rated as the most important at the first visit. The lack of knowledge about the duration of pregnancy and first pregnancies significantly predicted the need for pregnancy-related health education and lifestyle health education for pregnant women.

\section{Recommendations}

This study recommends that midwives and nurses should determine the specific health education needs of women at their first antenatal visit and that health education should be tailored to their individual needs. The health care facilities, especially in lowincome communities such as in Khayelitsha, should consider refresher training for nurses and midwives to allow them to remain up to date with the health information needs of pregnant women.

\section{Limitations of the Study}

The study sample focused on health education needs of pregnant women during their first antenatal attendance at two purposively selected PHC at Khayelitsha Health District (KHD), and therefore may not be generalisable to different settings. Nonetheless, these findings can be transferred to other pregnant women of low-income communities that experience health information needs, especially in southern Africa. There were pregnant women under 18 years who were excluded from the study due to the unavailability of parents or relatives to submit consent forms on their behalf.

\section{Acknowledgements}

We are grateful to Prof. Carol Shieh and colleagues for permission to use the research questionnaire. We thank pregnant women for their participation in this research. The facility managers, nurses and midwives' role in the research study sites are highly 
recognised and appreciated. The commitment and support of research assistants through the data collection process have contributed to the success of the study.

\section{References}

Al-Ateeq, M. A., and A. A. Al-Rusaiess. 2015. "Health Education during Antenatal Care: The Need for More." International Journal of Women's Health 7: 239. https://doi.org/10.2147/IJWH.S75164.

Amenu, G., Z. Mulaw, T. Seyoum, and H. Bayu. 2016. "Knowledge about Danger Signs of Obstetric Complications and Associated Factors Among Postnatal Mothers of Mechekel District Health Centers, East Gojjam Zone, Northwest Ethiopia, 2014." Scientifica 2016. https://doi.org/10.1155/2016/3495416.

Anya, S. E., A. Hydara, and L. E. Jaiteh. 2008. "Antenatal Care in the Gambia: Missed Opportunity for Information, Education and Communication." BMC Pregnancy and Childbirth 8 (1): 9. https://doi.org/10.1186/1471-2393-8-9.

Baron, R., Q. Heesterbeek, J. Manniën, E. K. Hutton, J. Brug, and M. J. Westerman. 2017. "Exploring Health Education with Midwives, as Perceived by Pregnant Women in Primary Care: A Qualitative Study in the Netherlands." Midwifery 46: 37-44. https://doi.org/10.1016/j.midw.2017.01.012.

Bjelke, M., A.-K. Martinsson, L. Lendahls, and M. Oscarsson. 2016. "Using the Internet as a Source of Information during Pregnancy: A Descriptive Cross-Sectional Study in Sweden." Midwifery 40: 187-191. https://doi.org/10.1016/j.midw.2016.06.020.

Brixval, C. S., S. F. Axelsen, S. K. Andersen, P. Due, and V. Koushede. 2014. "The Effect of Antenatal Education in Small Classes on Obstetric and Psycho-Social Outcomes: A Systematic Review and Meta-Analysis Protocol." Systematic Reviews 3 (1): 12. https://doi.org/10.1186/2046-4053-3-12.

Chib, A. 2010. "The Aceh Besar Midwives with Mobile Phones Project: Design and Evaluation Perspectives Using the Information and Communication Technologies for Healthcare Development Model." Journal of Computer-Mediated Communication 15 (3): 500-525. https://doi.org/10.1111/j.1083-6101.2010.01515.x.

Dako-Gyeke, P., M. Aikins, R. Aryeetey, L. Mccough, and P. B. Adongo. 2013. "The Influence of Socio-Cultural Interpretations of Pregnancy Threats on Health-Seeking Behavior among Pregnant Women in Urban Accra, Ghana." BMC Pregnancy and Childbirth 13 (1): 211. https://doi.org/10.1186/1471-2393-13-211. 
Gudayu, T. W., S. M. Woldeyohannes, and A. A. Abdo. 2014. "Timing and Factors Associated with First Antenatal Care Booking among Pregnant Mothers in Gondar Town; North West Ethiopia." BMC Pregnancy and Childbirth 14 (1): 287. https://doi.org/10.1186/1471-239314-287.

Hardie, K., D. Horsburgh, and S. Key. 2014. "Facilitating Antenatal Education Classes in Scotland." British Journal of Midwifery 22 (6): 409-416.

https://doi.org/10.12968/bjom.2014.22.6.409.

Hildingsson, I., H. Haines, M. Cross, J. F. Pallant, and C. Rubertsson. 2013. "Women's Satisfaction with Antenatal Care: Comparing Women in Sweden and Australia." Women and Birth 26 (1): e9-e14. https://doi.org/10.1016/j.wombi.2012.06.002.

Hofmeyr, G., and L. Mentrop. 2015. "Time for 'basic Antenatal Care Plus' in South Africa?" SAMJ: South African Medical Journal 105 (11): 902-903. https://doi.org/10.7196/SAMJ.2015.v105i11.10186.

Lam, W., W. W. To, and E. S. Ma. 2016. "Seatbelt Use by Pregnant Women: A Survey of Knowledge and Practice in Hong Kong." Hong Kong Med J 22 (5): 420-427. https://doi.org/10.12809/hkmj164853.

Maher, C. M., G. K. Spurling, and D. A. Askew. 2014. "Health and Well-Being of Urban Aboriginal and Torres Strait Islander Women at their First Antenatal Visit: A CrossSectional Study." Australian and New Zealand Journal of Obstetrics and Gynaecology 54 (1): 88-90. https://doi.org/10.1111/ajo.12159.

McArdle, A., V. Flenady, J. Toohill, J. Gamble, and D. Creedy. 2015. "How Pregnant Women Learn about Foetal Movements: Sources and Preferences for Information." Women and Birth 28 (1): 54-59. https://doi.org/10.1016/j.wombi.2014.10.002.

Naledi, T., H. Schneider, and P. Barron. 2011. "Primary Health Care in SA since 1994 and Implications of the New Vision for PHC Re-engineering." South African Health Review (1): 17-28.

Ohlendorf, J. M., M. E. Weiss, and P. Ryan. 2012. "Weight-management Information Needs of Postpartum Women." MCN: The American Journal of Maternal/Child Nursing 37 (1): 5663. https://doi.org/10.1097/NMC.0b013e31823851ee. 
Pérez-Lu, J. E., A. M. Bayer, and R. Iguiñiz-Romero. 2018. "Information= Equity? How Increased Access to Information can Enhance Equity and Improve Health Outcomes for Pregnant Women in Peru." Journal of Public Health 40 (suppl 2): ii64-ii73. https://doi.org/10.1093/pubmed/fdy177.

Pisa, F. E., A. Casetta, E. Clagnan, E. Michelesio, L. V. Brumatti, and F. Barbone. 2015. "Medication Use during Pregnancy, Gestational Age and Date of Delivery: Agreement between Maternal Self-Reports and Health Database Information in a Cohort." BMC Pregnancy and Childbirth 15 (1): 310. https://doi.org/10.1186/s12884-015-0745-3.

Rochat, T. J., R. M. Bland, M. Tomlinson, and A. Stein. 2013. "Suicide Ideation, Depression and HIV among Pregnant Women in Rural South Africa." Health 5 (3A): 650-661. https://doi.org/10.4236/health.2013.53A086.

Royal College of Midwives. 2013. "Maternal Mental Health: Improving Emotional Wellbeing in Postnatal Care." Accessed April 2, 2015. www.rcm.org.uk/getinvolved/campaigns/pressure-points.

Shieh, C., A. McDaniel, and I. Ke. 2009. "Information-Seeking and its Predictors in LowIncome Pregnant Women." Journal of Midwifery and Women's Health 54 (5): 364-372. https://doi.org/10.1016/j.jmwh.2008.12.017.

Solomon, A. A., A. Amanta, E. Chirkose, and M. B. Badi. 2015. "Knowledge about Danger Signs of Pregnancy and Associated Factors among Pregnant Women in Debra Birhan Town, Central Ethiopia." Sci J Public Health 3 (2): 269-273. https://doi.org/10.11648/j.sjph.20150302.27.

Song, H., E. M. Cramer, S. McRoy, and A. May. 2013. "Information Needs, Seeking Behaviors, and Support among Low-Income Expectant Women." Women and Health 53 (8): 824-842. https://doi.org/10.1080/03630242.2013.831019.

Vieira, N., D. N. Rasmussen, I. Oliveira, A. Gomes, P. Aaby, C. Wejse, ... H. W. Unger. 2017. "Awareness, Attitudes and Perceptions Regarding HIV and PMTCT amongst Pregnant Women in Guinea-Bissau: A Qualitative Study." BMC Women's Health 17 (1): 71. https://doi.org/10.1186/s12905-017-0427-6.

Vonderheid, S. C., K. F. Norr, and A. S. Handler. 2007. "Prenatal Health Promotion Content and Health Behaviors." Western Journal of Nursing Research 29 (3): 258-276. https://doi.org/10.1177/0193945906296568. 